\title{
Prevalence and multidrug resistance pattern of Salmonella isolated from resident wild birds of Bangladesh
}

\author{
Abdullah Al Faruq ${ }^{1}$, Mohammad Mahmudul Hassan², Mohammad Mejbah Uddin ${ }^{1}$, Mohammad Lutfur Rahman ${ }^{1}$,
} Tofazzal Md. Rakib ${ }^{3}$, Mahabub Alam ${ }^{4}$ and Ariful Islam ${ }^{5,6}$

\begin{abstract}
1. Department of Anatomy and Histology, Faculty of Veterinary Medicine, Chittagong Veterinary and Animal Sciences University, Chittagong 4225, Bangladesh; 2. Department of Physiology, Biochemistry and Pharmacology, Faculty of Veterinary Medicine, Chittagong Veterinary and Animal Sciences University, Chittagong 4225, Bangladesh; 3. Department of Pathology and Parasitology, Faculty of Veterinary Medicine, Chittagong Veterinary and Animal Sciences University, Chittagong 4225, Bangladesh; 4. Department of Animal Science and Nutrition, Faculty of Veterinary Medicine, Chittagong Veterinary and Animal Sciences University, Chittagong 4225, Bangladesh; 5. EcoHealth Alliance, New York, NY, USA; 6. Institute of Epidemiology, Disease Control and Research (IEDCR), Mohakhali 1212, Bangladesh.

Corresponding author: Mohammad Mahmudul Hassan, e-mail: miladhasan@yahoo.com,

AAF: faruqabdullahal103@gmail.com, MMU: mmu_cvasu@yahoo.com, MLR: labibacvasu2012@yahoo.com, TMR: rakibtofazzal367@gmail.com, MA: mahabub38@yahoo.com, AI: arif@ecohealthalliance.org Received: 05-08-2016, Accepted: 19-09-2016, Published online: 01-10-2016
\end{abstract}

doi: 10.14202/IJOH.2016.35-41 How to cite this article: Faruq AA, Hassan MM, Uddin MM, Rahman ML, Rakib TM, Alam M, Islam A. Prevalence and multidrug resistance pattern of Salmonella isolated from resident wild birds of Bangladesh. Int J One Health 2016;2:35-41.

\begin{abstract}
Aim: Salmonellosis is one of the most common zoonotic diseases, and the presence of antimicrobial resistant Salmonella in wild birds is global public health threat. Throughout the last decades, multidrug resistance of Salmonella spp. has increased, particularly in developing countries. Therefore, a cross-sectional study was conducted to investigate the prevalence of Salmonella spp. and antimicrobial resistance pattern against Salmonella spp. from two species of resident wild birds namely house crow (Corvus splendens) and Asian pied starling (Gracupica contra).
\end{abstract}

Materials and Methods: Samples were collected from cloacal swabs of house crows and Asian pied starling for isolating Salmonella spp. (bacteriological culture methods) followed by antimicrobial susceptibility testing (disk diffusion method) against Salmonella spp. isolates during March to December 2014.

Results: The prevalence of Salmonella in Asian pied starling and house crows were $67 \%$ and $65 \%$, respectively. Within the category of samples from different species, the variation in prevalence was not varied significantly $(\mathrm{p}>0.05)$. Isolated Salmonella spp. was tested for resistance to six different antimicrobial agents. Among six antimicrobial tested, 100\% resistance were found to penicillin, oxacillin, and clindamycin followed by erythromycin (50-93\%), kanamycin (7-20\%), and cephalothin (30-67\%) from both species of birds. Kanamycin remained sensitive in (70-73\%), cephalothin (26-70\%), and erythromycin appeared to be (0-30\%) sensitive against Salmonella spp. isolates. Isolated Salmonella spp. was multidrug resistant up to three of the six antimicrobials tested.

Conclusion: It can be said that the rational use of antimicrobials needs to be adopted in the treatment of disease for livestock, poultry, and human of Bangladesh to limit the emergence of drug resistance to Salmonella spp.

Keywords: antimicrobial, prevalence, resistance, resident wild birds, Salmonella.

\section{Introduction}

Salmonella has been renowned as a significant pathogen that can contaminate human and animals consequential in major morbidity and mortality [1]. Salmonella spp. was recognized as a major cause of food and waterborne illnesses in many countries that are closely associated with the presence of resident wild birds in the vicinity of domestic one where wild birds were a major carrier for this Salmonella spp. Most of the Salmonellosis is zoonotic in origin [2]. Salmonellosis has been found to be major infectious

Copyright: Faruq, et al. This article is an open access article distributed under the terms of the Creative Commons Attribution 4.0 International License (http://creativecommons.org/licenses/ by/4.0/), which permits unrestricted use, distribution, and reproduction in any medium, provided you give appropriate credit to the original author(s) and the source, provide a link to the Creative Commons license, and indicate if changes were made. The Creative Commons Public Domain Dedication waiver (http:// creativecommons.org/ publicdomain/zero/1.0/) applies to the data made available in this article, unless otherwise stated. diseases of all ages of birds. This disease is endemic in many developing countries, particularly the Asian subcontinent and, South and Central America.

Salmonellosis is a major problem in poultry industries of Bangladesh and its prevalence ranged from $7 \%$ to $53.3 \%$ [3-5]. The probable cause for spreading of this disease can be Salmonella carrying wild birds, from them Salmonella spread into livestock and human. In recent years, problems related to Salmonella have increased significantly, both in terms of the incidence and severity of cases of human Salmonellosis. Heavy use of antibiotics for medical and veterinary purposes [6,7], as well as the domestic and agricultural use of pesticides and related compounds [7], caused significant antibiotic contamination of the natural environment and consequent development of resistance in communities.

In veterinary practice, antibiotics are used in livestock production, disease prevention, and as 
growth-promoting feed additives, and due to indiscriminate use of antimicrobials, the drug residues were deposited in the environment and also in the food animals tissues [8,9] which ultimately causes antimicrobial resistance. The use of antibiotics in animals disrupts normal flora of intestine, resulting into emergence of antibiotic-resistant Salmonella and their prolonged fecal shedding into the environment. Such practice has led to misuse of antibiotics with the associated high prevalence of antibiotic resistance among isolates from animal and food sources [10]. Effluents from environments (hospitals and slaughterhouses) are alarming risk for clinician to treat the patient with antibiotics due to harboring antibiotic resistance bacteria [11-13]. A growing body of evidence implicates environmental organisms as reservoirs of these resistance genes, antibiotic resistance, evolving and spreading among bacterial pathogens, poses a serious threat to human health. There are reports of a high prevalence of resistance in Salmonella isolates from countries such as Taiwan, India, and The Netherlands and resistant isolates from France, Canada, and Ethiopia. Similarly, there are various reports of multidrug resistant Salmonella organisms isolated in Bangladesh. Recently, antimicrobial resistance Salmonella spp. isolated from commercial layer eggs, eggshell surface, and egg-storing trays in Bangladesh [12]. However, resistance has also been found in the absence of antibiotic exposure, such as in bacteria from wildlife $[14,15]$. Most research on the epidemiology of antibiotic resistance spreading has paying attention on human and veterinary medicine, but there is a rising interest to recognize how bacterial resistance is transferred within reservoirs in natural environments [16]. Due to their diversity in migratory patterns and ecological niches, and their ease in picking up human/environmental bacteria, they act as mirrors of human activities. In addition, bird migration provides a possible mechanism for the establishment of new endemic foci of disease at great distances from where an infection was first acquired [17]. Besides, due to large range of migration and flying of wild birds close to the human settlement may cause drug resistance.

Some opportunistic and nonstructural studies had been conducted for Salmonella in commercial poultry in Bangladesh. Very few studies were conducted on isolation and drug resistance in Salmonella spp. throughout the world from wild birds but none in Bangladesh. This study, therefore, aimed to investigate the prevalence of Salmonella spp. in two species of wild birds (house crow and Asian pied starling) and antimicrobial resistance pattern against Salmonella isolates from those resident wild birds.

\section{Materials and Methods}

\section{Ethical approval}

The current study was approved by the Animal Ethical Experimentation Committee (CVASU-AEEC) of Chittagong Veterinary and Animal Sciences University, Bangladesh.

\section{Study design}

A cross-sectional study was conducted in two areas of Chittagong. The current study was conducted at Pahartoli and Bakolia of Chittagong City Corporation (CCC) during March to December 2014.

\section{Sample collection and preservation}

A total of 100 cloacal samples were collected from the resident wild bird that were trapped using misnet and from which 40 samples were house crows and 60 were Asian pied starling. A sterile cotton swab stick was used to collect the cloacal sample and then put the stick immediately into a sterile vial containing $6 \mathrm{ml}$ amines transport media (Oxoid) and kept in a cool box $\left(4^{\circ} \mathrm{C}\right)$. The samples were then transferred to the Poultry Research and Training Center (PRTC) laboratory under sterile conditions and processed for the isolation of Salmonella spp.

\section{Salmonella isolation and identification procedures}

The study was conducted utilizing the conventional methods for the detection of Salmonella spp. following the standard guidelines. There were four definite sequential steps: (1) Nonselective preenrichment, (2) selective enrichment, (3) plating out and identification, and (4) confirmation using triple sugar iron (TSI) agar. Buffered peptone water was used as nonselective preenrichment broth. Xylose lysine deoxycholate (XLD) was used as selective enrichment broth. After incubation, a loop full of broth was streaked on XLD medium and incubated at $37^{\circ} \mathrm{C}$ for $24 \mathrm{~h}$. Colonies with black centers were considered presumptive Salmonella spp., for plating out and identification Salmonella-Shigella (SS) agar was used. The depth of the agar in the Petri dishes were maintained approximately at $4 \mathrm{~mm}$. The plates were incubated at $37^{\circ} \mathrm{C} \pm 1^{\circ} \mathrm{C}$ for $24 \pm 3 \mathrm{~h}$. The plates were incubated in an inverted position. After incubation, the plates were checked for the development of typical Salmonella colonies. Typical colonies of Salmonella on SS agar were blackish. TSI agar was used to see the typical colonies and biochemical reactions for the identification of Salmonella spp. typical colonies grown on the SS agar plates were transferred and inoculated in TSI agar slant and incubated at $37^{\circ} \mathrm{C} \pm 1^{\circ} \mathrm{C}$ for $24 \pm 3 \mathrm{~h}$. The TSI agar slant surface was streaked, and the butt was stabbed and incubated at $37^{\circ} \mathrm{C} \pm 1^{\circ} \mathrm{C}$ for $24 \pm 3 \mathrm{~h}$.

\section{Selection of antimicrobials for antimicrobial suscep- tibility testing}

In the present research, the Salmonella isolates were tested with antimicrobial sensitivity testing to see whether they are resistant to antimicrobials (penicillin, erythromycin, clindamycin, oxacillin, kanamycin, and cephalothin) used in Bangladesh.

\section{Antimicrobial sensitivity test}

The antimicrobial sensitivity testing was done by the disk diffusion method as described by NCCLS 
2000, now known as the Clinical and Laboratory Standards Institute [18]. Mueller-Hinton agar was used for this testing. The agar was prepared as per the instructions provided by the manufacturer. McFarland 0.5 turbidity standards were prepared as per the standard guidelines described by the CLSI. The predetermined battery of antimicrobial disks such as penicillin (10 units/disc), cephalothin $(30 \mu \mathrm{g} /$ disc), oxacillin $(1 \mu \mathrm{g} / \mathrm{disc})$, kanamycin $(30 \mu \mathrm{g} / \mathrm{disc})$, erythromycin $(15 \mu \mathrm{g} / \mathrm{disc})$, and clindamycin $(2 \mu \mathrm{g} /$ disc) were chosen and placed centrally onto the surface of the inoculated agar plate. The disk placed in the agar surface was not closer than $24 \mathrm{~mm}$ from center to center. A total of six disks were placed on one $150 \mathrm{~mm}$ plate. The plates were inverted and placed in an incubator set to $35^{\circ} \mathrm{C}$ within $15 \mathrm{~min}$ after the disks were applied. After 16-18 h of incubation, each plate was examined.

The resulting zone of inhibition was uniformly circular with a confluent lawn of growth. The diameters of the zones of complete inhibition were measured, including the diameter of the disk. Zones were measured to the nearest whole millimeter, using a suitable scale, which held on the back of the inverted Petri plate. The sizes of zones of inhibition were interpreted by referring to zone diameter interpretive standards from NCCLS 2000 [19], and the isolates were considered as sensitive, intermediately sensitive, or resistant to these agents tested according to the standard [18].

\section{Data analysis}

Field and laboratory data were stored and then cleaned in the MS Excel-2007 program before exporting to STATA/IC-13.0 for analysis. Descriptive analysis was performed to know the frequency and distribution of Salmonella and antibiotic resistance pattern.

\section{Results}

Salmonella spp. was isolated from cloacal sample on two species of wild birds such as crow and Asian pied starling at Pahartoli and Bakolia under $\mathrm{CCC}$ areas of Bangladesh to evaluate antimicrobial susceptibility to estimate the prevalence and pattern of antimicrobial resistance among Salmonella spp. isolates.

Table-1 shows the prevalence of Salmonella spp. within two species of resident wild birds. The prevalence of Asian pied starling and house crow was $67 \%$ and $65 \%$, respectively. Within the category of samples from different species, the variation in prevalence was not varied significantly ( $>0.05)$. The strength of association between the prevalence of Salmonella spp. within house crow and Asian pied starling were $1.4 \%$, where the strength of association was $1.4 \%$ higher in Asian pied starling than house crows.

From house crow, resistance patterns of Salmonella were highest in penicillin, oxacillin, and clindamycin $(100 \%)$ followed by erythromycin $(50 \%)$, cephalothin $(30 \%)$, and kanamycin $(20 \%)$. It was revealed that no isolates were found sensitive to
Table-1: Prevalence of Salmonella spp. within two species of resident wild birds.

\begin{tabular}{lccc}
\hline Species & Positive (\%) & $\chi^{2}$-value & p value \\
\hline $\begin{array}{l}\text { House } \\
\text { crows }(\mathrm{N}=40)\end{array}$ & $26(65)$ & 0.014 & 0.9 \\
$\begin{array}{l}\text { Asian pied } \\
\text { starling }(\mathrm{N}=60)\end{array}$ & $40(67)$ & & \\
\hline
\end{tabular}

penicillin, oxacillin, and clindamycin. Kanamycin and cephalothin showed the highest level of sensitivity $(70 \%)$ followed by erythromycin (30\%). In the current research, all the isolates of Salmonella showed multiple antimicrobial resistances (Table-2).

The Asian pied starling resistance patterns of Salmonella were highest in penicillin, oxacillin, and clindamycin $(100 \%)$ followed by erythromycin (93\%), cephalothin (67\%), and kanamycin (7\%). It was revealed that no isolates were found sensitive to penicillin, oxacillin, and clindamycin. Kanamycin showed the highest level of sensitivity (73\%) followed by cephalothin $(26 \%)$. In the current research, all the isolates of Salmonella showed multiple antimicrobial resistances (Table-3).

Among the six tested antimicrobials resistance pattern against Salmonella isolates penicillin, oxacillin, and clindamycin turned out as the highest level of resistance $(100 \%)$ followed by erythromycin (50-93\%), cephalothin (30-67\%), and kanamycin (7-20\%) from house crows and Asian pied starling. The rate of sensitivity to individual antibiotics against Salmonella isolates from two different species of birds was highest in kanamycin ranged (70-73\%) followed by cephalothin $(26-70 \%)$ and erythromycin $(0-30 \%)$. Penicillin, oxacillin, and clindamycin showed no variation of resistance level; it was $(100 \%)$ resistance in two species of birds and no isolates were found to sensitive against these three antibiotics. In case of erythromycin, 93\% of Salmonella isolates from Asian pied starling and $50 \%$ from house crows were resistance to erythromycin. Antimicrobial resistance of kanamycin was found in crows $(20 \%)$ and Asian pied starling (7\%). The resistance level of cephalothin was higher in Asian pied starling (67\%) and lower in house crows (30\%). The sensitivity of kanamycin and cephalothin to isolated Salmonella spp. was better within two species of birds among all used antibiotics. Highest resistance pattern for intermediate type was in kanamycin ranged (10-20\%) followed by erythromycin $(7-20 \%)$, cephalothin $(0-7 \%)$, and $(0 \%)$ for other three antibiotics to isolated Salmonella for both species of birds. Highest intermediate type resistance was found (20\%) to isolated Salmonella spp. from Asian pied starling in both kanamycin and erythromycin (Table-4).

\section{Discussion}

House crow (Corvus splendens) and Asian pied starling (Gracupica contra) are very much common in our country, especially in the major city areas. They 
Table-2: Antimicrobial resistance pattern of Salmonella isolates from house crows.

\begin{tabular}{lcccc}
\hline Antibiotics & Number of positive samples tested & \multicolumn{2}{c}{ Pattern (\%) } \\
\cline { 3 - 5 } & & Resistance & Intermediate & Sensitive \\
\hline Penicillin & 20 & 100 & 0 & 0 \\
Erythromycin & 20 & 50 & 20 & 30 \\
Oxacillin & 20 & 100 & 0 & 0 \\
Kanamycin & 20 & 20 & 0 & 70 \\
Clindamycin & 20 & 100 & 0 & 70 \\
Cephalothin & 20 & 30 & 0 & 0 \\
\hline
\end{tabular}

Table-3: Antimicrobial resistance pattern of Salmonella isolates from Asian pied starling.

\begin{tabular}{lcccc}
\hline Antibiotics & Number of positive samples tested & \multicolumn{2}{c}{ Pattern(\%) } \\
\cline { 3 - 5 } & & Resistance & Intermediate & Sensitive \\
\hline Penicillin & 25 & 100 & 0 & 0 \\
Erythromycin & 25 & 93 & 7 & 0 \\
Oxacillin & 25 & 100 & 0 & 0 \\
Kanamycin & 25 & 7 & 0 & 73 \\
Clindamycin & 25 & 100 & 7 & 0 \\
Cephalothin & 25 & 67 & & 26 \\
\hline
\end{tabular}

Table-4: Patterns of multidrug resistance in isolates of Salmonella from two different species.

\begin{tabular}{|c|c|c|c|c|}
\hline Antimicrobials & Pattern & House crows $(\mathrm{N}=20)(\%)$ & Asian pied starling $(\mathrm{N}=25)(\%)$ & Range (\%) \\
\hline \multirow[t]{3}{*}{ Penicillin } & $\mathrm{R}$ & 100 & 100 & 100 \\
\hline & I & 0 & 0 & 0 \\
\hline & $\mathrm{S}$ & 0 & 0 & 0 \\
\hline \multirow[t]{3}{*}{ Erythromycin } & $\mathrm{R}$ & 50 & 93 & $50-93$ \\
\hline & $\mathrm{I}$ & 20 & 7 & $7-20$ \\
\hline & $\mathrm{S}$ & 30 & 0 & $0-30$ \\
\hline \multirow[t]{3}{*}{ Oxacillin } & $\mathrm{R}$ & 100 & 100 & 100 \\
\hline & $\mathrm{I}$ & 0 & 0 & 0 \\
\hline & $\mathrm{S}$ & 0 & 0 & 0 \\
\hline \multirow[t]{3}{*}{ Kanamycin } & $\mathrm{R}$ & 20 & 7 & $7-20$ \\
\hline & I & 10 & 20 & $10-20$ \\
\hline & $\mathrm{S}$ & 70 & 73 & $70-73$ \\
\hline \multirow[t]{3}{*}{ Clindamycin } & $\mathrm{R}$ & 100 & 100 & 100 \\
\hline & I & 0 & 0 & 0 \\
\hline & $\mathrm{S}$ & 0 & 0 & 0 \\
\hline \multirow[t]{3}{*}{ Cephalothin } & $\mathrm{R}$ & 30 & 67 & $30-67$ \\
\hline & I & 0 & 7 & $0-7$ \\
\hline & $\mathrm{S}$ & 70 & 26 & $26-70$ \\
\hline
\end{tabular}

$\mathrm{R}=$ Resistance, $\mathrm{I}=$ Intermediate, $\mathrm{S}=$ Sensitive

are usually carrion eaters and take their foods from the garbage of city areas. Nowadays, for the easy and frequent access of these two species in rural and urban area where different antibiotics are used regularly for human and livestock treatment, house crow and Asian pied starling got some antibiotic residue or antibiotic resistant bacteria from those human and livestock source anyway and they developed antibiotic resistance against some bacterial pathogens, such as Salmonellosis, which have important public health significance.

The prevalence of Salmonella in crow was $65 \%$ which was very much higher than the result of previous research isolated from crows cloaca [20]. The prevalence of Salmonella in Asian pied starling was $67 \%$ which was also very much higher than the previous studies [21,22] on European starlings. Research conducted by isolation of $S$. enterica from gastrointestinal tract samples of European starling showed $2.5 \%$ prevalence [23] which is much lower than the current study. The higher prevalence rate of the present study may be due to overpopulated environment of Bangladesh and more frequent presence of house crow and Asian pied starling as a store house for microorganisms including Salmonella spp. [11,13]. The favorable climatic condition and substandard hygienic condition of Bangladesh may also contribute to a higher prevalence rate of Salmonella.

Approaches to prevent and control Salmonellosis in the food animal industry by extensive use of antibiotics [24] has led to emergence of resistant bacteria [25] through mutation and acquisition of resistance encoding genes [26]. The situation in developing countries such as Bangladesh may be exaggerated by 
easy accessibility of antimicrobials at a lower price and their extensive use in poultry production system [27]. The current study recorded multiple antimicrobial resistances against Salmonella spp. (up to six) and in most cases, estimated $100 \%$ resistance to $2-4$ antimicrobials across the study sites. These threatening correspond to the many nonepidemiological and opportunistic earlier studies in Bangladesh [28,29], India [30], Nepal, and Bhutan. The results of present study revealed that all the Salmonella isolates from cloacal swab of crows and Asian pied starling were resistance to penicillin which has the similarity with earlier studies [31-33]. Several previous researches [32,34,35] found 100 resistance of oxacillin against Salmonella both in house crow and Asian pied starling. Erythromycin was resistance more against Salmonella spp. isolated from Asian pied starling (93\%) than the resistance against Salmonella spp. isolated from house crows $(50 \%)$. This results varied with many other previous studies where they said erythromycin were totally resistant to Salmonella spp. [32,36,37]. The lower resistance of kanamycin found in the current study has more or less similarity with the result of different scientist where kanamycin resistance to Salmonella spp. was 18-60\% [38-41], and it is good news for Bangladesh because it may be used effectively against Salmonella. Clindamycin showed 100\% resistance against Salmonella, which found the similarity with the result of others similar researches [42-45]. Cephalothin was resistance more against Salmonella spp. isolated from Asian pied starling (67\%) than the resistance against Salmonella spp. isolated from house crows $(30 \%)$. This result was more or less similar with many other previous studies where they said cephalothin was slightly resistant to Salmonella spp. [46].

Penicillin, oxacillin, erythromycin, kanamycin, clindamycin, and cephalothin antibiotics are commonly used in livestock, poultry, and human treatment in Bangladesh. Therefore, residues of these antibiotics could have been passed through different environmental sources to the birds or they found antibiotic resistant Salmonella spp. from those sources during their migration. The high resistance of antibiotic to Salmonella spp. from cloacal swabs of house crow and Asian pied starling of the present study might be due to indiscriminate use of these antibiotics to human as well as in livestock. That's why wild birds got the antibiotic resistant Salmonella spp. or residues of those antibiotics by taking the dung or stool or other wastage of those livestock, poultry, or human. In addition, sometimes farmers select drugs by their own or rely on neighbor experienced farmers or nonveterinarians and these malpractices may not always ensure proper drugs doses, frequency of drug administration and complete course of drug treatment those can be a major cause for the establishment of antibiotic resistant Salmonella spp.

\section{Conclusion}

Salmonellosis is a leading, zoonotic, and widely distributed disease throughout the world. The level of resistance of Salmonella to antibiotics is an alarming issue to the human and livestock. Therefore, it is necessary to inform people about the future alarming condition of the antibiotic resistance. There is need for more rational use of antibiotics in animal production and more careful use in humans. It is important to take concerted action to improve antibiotic resistance surveillance capacity worldwide with a view to monitoring the emerging resistance genes and their transfer in both animal and human. In addition, alternatives to antibiotics should be explored such as the application of probiotics in poultry for production of safe edible products. To control Salmonella infection of wild birds in Bangladesh detailed epidemiological investigation is needed. Proper disposal of dustbin content, sewage water, dead carcass, waste food, and human stool should be needed to prevent transmission of Salmonella infection.

\section{Authors' Contributions}

$\mathrm{AAF}$ and $\mathrm{MMH}$ conducted the research and actively prepared the manuscript. AAF, MMH, MA, and AI designed the work and provided the information. MMU, MLR, AI, and TMR participated in the manuscript preparation and advice during the research work. All the authors read and approved the final manuscript.

\section{Acknowledgments}

The authors are grateful to the Chittagong Veterinary and Animal Sciences University, for providing financial (grant reference no. UGC/PUB/ CVASU: P013) and technical support, and PRTC for laboratory facilities, to the project. This study was benefited from intellectual contributions from the PREDICT project of the United States Agency for International Development (USAID) Emerging Pandemic Threats Program.

\section{Competing Interests}

The authors declare that they have no competing interests.

\section{References}

1. Akkina JE, Hogue AT, Angulo FJ, Johnson R, Petersen KE, Saini PK, et al. Epidemiologic aspects, control, and importance of multiple-drug resistant Salmonella Typhimurium DT104 in the United States. J Am Vet Med Assoc 1999;214:790-8.

2. Steve Yan S, Pendrak ML, Abela-Ridder B, Punderson JW, Fedorko DP, Foley SL. An overview of Salmonella typing: Public health perspectives. Clin Appl Immunol Rev 2004;4:189-204.

3. Uddin M, Ahmed S, Hassan M, Khan S, Mamun M. Prevalence of poultry diseases at Narsingdi, Bangladesh. Int J BioRes 2010;1:09-13.

4. Mahmud MS, Bari ML, Hossain MA. Prevalence of Salmonella serovars and antimicrobial resistance profiles in poultry of Savar area, Bangladesh. Foodborne Pathog Dis 
2011;8:1111-8.

5. Rahman M, Samad M, Rahman M, Kabir S. Bacteriopathological studies on salmonellosis, colibacillosis and pasteurellosis in natural and experimental infections in chickens. Bangladesh J Vet Med 2004;2:1-8.

6. White DG, Piddock LJ, Maurer JJ, Zhao S, Ricci V, Thayer SG. Characterization of fluoroquinolone resistance among veterinary isolates of avian Escherichia coli. Antimicrob Agents Chemother 2000;44:2897-9.

7. Balagué C, Véscovi EG. Activation of multiple antibiotic resistance in uropathogenic Escherichia coli strains by aryloxoalcanoic acid compounds. Antimicrob Agents Chemother 2001;45:1815-22.

8. Sattar S, Hassan MM, Islam S, Alam M, Faruk M, Chowdhury $\mathrm{S}$, et al. Antibiotic residues in broiler and layer meat in Chittagong District of Bangladesh. Vet World 2014;7:738-43.

9. Hassan MM, Amin KB, Ahaduzzaman M, Alam M, Al Faruk MS, Uddin I. Antimicrobial resistance pattern against E. coli and Salmonella in layer poultry. Res J Vet Pract 2014;2:30-5

10. Chowdhury S, Hassan MM, Alam M, Sattar S, Bari MS, Saifuddin AK, et al. Antibiotic residues in milk and eggs of commercial and local farms at Chittagong, Bangladesh. Vet World 2015;8:467-71.

11. Hassan MM, Ahaduzzaman M, Alam M, Bari MS, Amin KA, Faruq AA. Antimicrobial resistance pattern against $E$. coli and Salmonella spp. in environmental effluents. Int J Nat Sci 2015;5:52-8.

12. Mahmud T, Hassan MM, Alam M, Khan MM, Bari MS, Islam A. Prevalence and multidrug-resistant pattern of Salmonella from the eggs and egg-storing trays of retail markets of Bangladesh. Int J One Health 2016;2:7-11.

13. Ahaduzzaman M, Hassan MM, Alam M, Islam S, Uddin I. Antimicrobial resistance pattern against Staphylococcus aureus in environmental effluents. Res J Vet Pract 2014;2:13-6.

14. Wellington EM, Boxall AB, Cross P, Feil EJ, Gaze WH, Hawkey PM, et al. The role of the natural environment in the emergence of antibiotic resistance in gram-negative bacteria. Lancet Infect Dis 2013;13:155-65.

15. Tacão M, Correia A, Henriques I. Resistance to broad-spectrum antibiotics in aquatic systems: Anthropogenic activities modulate the dissemination of bla(CTX-M)-like genes. Appl Environ Microbiol 2012;78:4134-40.

16. Allen HK, Donato J, Wang HH, Cloud-Hansen KA, Davies J, Handelsman J. Call of the wild: Antibiotic resistance genes in natural environments. Nat Rev Microbiol 2010;8:251-9.

17. Reed KD, Meece JK, Henkel JS, Shukla SK. Birds, migration and emerging zoonoses: West nile virus, lyme disease, influenza A and enteropathogens. Clin Med Res 2003;1:5-12

18. CLSI. Performance Standards for Antimicrobial Susceptibility Testing; Seventeenth Informational Suppliment. Vol. 26, 27. Wayne, PA: CLSI; 2007.

19. Wikler MA. Performance Standards for Antimicrobial Susceptibility Testing: Seventeenth Informational Supplement. Wayne, PA: Clinical and Laboratory Standards Institute; 2007.

20. Asagi M, Oka C, Sato G. Isolation of Salmonella Typhimurium var. Copenhagen from crows in the city of Otaru. Nihon Juigaku Zasshi 1976;38:521-2.

21. Snoeyenbos GH, Morin EW, Wetherbee DK. Naturally occurrine Salmonella in "blackbirds" and gulls. Avian Dis 1967;11:642-6.

22. Morishita TY, Aye PP, Ley EC, Harr BS. Survey of pathogens and blood parasites in free-living passerines. Avian Dis 1999;43:549-52.

23. Carlson JC, Franklin AB, Hyatt DR, Pettit SE, Linz GM. The role of starlings in the spread of Salmonella within concentrated animal feeding operations. J Appl Ecol
2011;48:479-86

24. Zhao S, McDermott PF, White DG, Qaiyumi S, Friedman SL, Abbott JW, et al. Characterization of multidrug resistant Salmonella recovered from diseased animals. Vet Microbiol 2007;123:122-32.

25. Oldfield EC. The road to resistance: Antibiotics as growth promoters for animals. Am J Gastroenterol 2003;98:499.

26. White DG, Zhao S, Sudler R, Ayers S, Friedman S, Chen S, et al. The isolation of antibiotic-resistant Salmonella from retail ground meats. N Engl J Med 2001;345:1147-54.

27. Fluit AC. Towards more virulent and antibiotic-resistant Salmonella? FEMS Immunol Med Microbiol 2005;43:1-11.

28. Prakash B, Krishnappa G, Muniyappa L, Kumar BS. Epidemiological characterization of avian Salmonella enterica serovar infections in India. Int $\mathrm{J}$ Poult Sci 2005;4:388-95

29. Begum K, Reza TA, Haque M, Hossain A, Hassan FK, Hasan SN, et al. Isolation, identification and antibiotic resistance pattern of Salmonella spp. from chicken eggs, intestines and environmental samples. Bangladesh Pharm J 2010;13:23-7.

30. Ahmed M, Rahman M, Mahbub K, Wahiduzzaman M. Characterization of antibiotic resistant Salmonella spp isolated from chicken eggs of Dhaka city. J Sci Res 2010;3:191.

31. Suresh T, Hatha AA, Sreenivasan D, Sangeetha N, Lashmanaperumalsamy P. Prevalence and antimicrobial resistance of Salmonella enteritidis and other salmonellas in the eggs and egg-storing trays from retail markets of Coimbatore, South India. Food Microbiol 2006;23:294-9.

32. McHugh GL, Moellering RC, Hopkins CC, Swartz MN. Salmonella Typhimurium resistant to silver nitrate, chloramphenicol, and ampicillin. Lancet 1975;1:235-40.

33. Roantree RJ, Kuo TT, MacPhee DG. The effect of defined lipopolysaccharide core defects upon antibiotic resistances of Salmonella Typhimurium. J Gen Microbiol 1977; 103:223-34.

34. Fu KP, Neu HC. Piperacillin, a new penicillin active against many bacteria resistant to other penicillins. Antimicrob Agents Chemother 1978;13:358-67.

35. Guzmán-Blanco M, Casellas JM, Sader HS. Bacterial resistance to antimicrobial agents in Latin America. The giant is awakening. Infect Dis Clin North Am 2000;14:67-81, viii.

36. Nishino K, Nikaido E, Yamaguchi A. Regulation of multidrug efflux systems involved in multidrug and metal resistance of Salmonella enterica serovar Typhimurium. J Bacteriol 2007;189:9066-75.

37. Jacobs-Reitsma WF, Koenraad PM, Bolder NM, Mulder RW. In vitro susceptibility of Campylobacter and Salmonella isolates from broilers to quinolones, ampicillin, tetracycline, and erythromycin. Vet Q 1994;16:206-8.

38. Cui S, Ge B, Zheng J, Meng J. Prevalence and antimicrobial resistance of Campylobacter spp. and Salmonella serovars in organic chickens from Maryland retail stores. Appl Environ Microbiol 2005;71:4108-11.

39. Groisman EA, Parra-Lopez C, Salcedo M, Lipps CJ, Heffron F. Resistance to host antimicrobial peptides is necessary for Salmonella virulence. Proc Natl Acad Sci U S A 1992;89:11939-43

40. Davis MA, Hancock DD, Besser TE, Rice DH, Gay JM, Gay $\mathrm{C}$, et al. Changes in antimicrobial resistance among Salmonella enterica serovar Typhimurium isolates from humans and cattle in the Northwestern United States, 19821997. Emerg Infect Dis 1999;5:802-6.

41. Besser TE, Goldoft M, Pritchett LC, Khakhria R, Hancock DD, Rice DH, et al. Multiresistant Salmonella Typhimurium DT104 infections of humans and domestic animals in the Pacific Northwest of the United States. Epidemiol Infect 2000;124:193-200.

42. Carattoli A. Plasmid-mediated antimicrobial resistance in Salmonella enterica. Curr Issues Mol Biol 2003;5:113-22.

43. Helmuth R. Antibiotic resistance in Salmonella. Salmonella in Domestic Animals. New York: CABI Publishing; 2000. 
p. 89-106.

44. Ang JY, Ezike E, Asmar BI. Antibacterial resistance. Indian J Pediatr 2004;71:229-39.

45. Keelara S, Scott HM, Morrow WM, Gebreyes WA, Correa M, Nayak R, et al. Longitudinal study of distributions of similar antimicrobial-resistant Salmonella serovars in pigs and their environment in two distinct swine production systems. Appl Environ Microbiol 2013;79:5167-78.

46. Maragkoudakis PA, Mountzouris KC, Psyrras D, Cremonese S, Fischer J, Cantor MD, et al. Functional properties of novel protective lactic acid bacteria and application in raw chicken meat against Listeria monocytogenes and Salmonella enteritidis. Int J Food Microbiol 2009;130:219-26.

$* * * * * * * *$ 